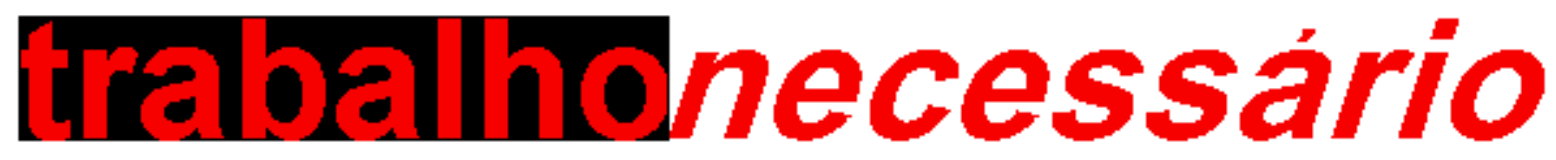

issn: $1808-799 \mathrm{X}$

ano 4 - número 4 - 2006

\title{
CIDADE, TRABALHO E CULTURA NA RUA \\ UM ESTUDO SOBRE A FORMAÇÃO ESTÉTICO-CULTURAL DOS TRABALHADORES E AS POLÍTICAS CULTURAIS NO RIO DE JANEIRO*
}

Viviane de Souza Rodrigues ${ }_{-}^{* *}$

\begin{abstract}
A CIDADE
O Rio Das Reformas

A modernidade insinua reformas no espaço urbano a fim de (re)desenhar a cidade em busca do progresso, assim, faz-se necessário "demolir" o passado, modernizando o presente como signo de construção civilizatória pelos moldes do capitalismo mundial. Sob esses pressupostos, muitos países buscaram a inserção no contexto da modernidade no século $X X$.

Nesse sentido, destaca-se nesse trabalho o contexto brasileiro, localizando as reflexões no Rio de Janeiro pelo seu emblema de capitalidade desde o século XVIII, que passou a ser intensificado na República na medida em que a cidade tornou-se exemplo de ruptura com o passado imperial e, por conseguinte, de inserção do país na modernidade. Assim, as reformas urbanas na cidade do Rio de Janeiro empreendidas entre 1902 e 1906 na administração do prefeito Pereira Passos, sob o governo do presidente Rodrigues Alves, foram justificadas pelas demandas políticas e econômicas tendo em vista a adequação do país aos padrões modernos de economia mundial, sobretudo, com o objetivo de atrair investimentos internacionais. (Lessa, 2001, p. 187)

Para tanto, as reformas urbanísticas realizadas na administração do prefeito Pereira Passos buscaram desenvolver a remodelação da imagem da cidade com ações urbanísticas, arquitetônicas e sanitárias, influenciando diretamente os padrões e hábitos
\end{abstract}


cariocas.

A continuidade histórica da modernização urbana foi realizada sob um processo reativo à desordem capitalista pela aglomeração residencial na cidade através de ações higienistas, sobretudo, como forma de regulação social baseado no ideário que estigmatizava a população como miserável e portadora de doenças e vícios. Desta forma, foram aterrados pântanos e desmontados morros, acarretando mudanças nas condições higiênicas das habitações, como também foram realizadas campanhas sanitárias de combate à febre amarela. (Lessa, 2001, pp. 194-195)

Nesse tempo também as reformas implicaram no (re)desenho urbanístico da cidade sob a perspectiva de ampliação, com a construção de avenidas largas e grandes como a avenida Central e a Beira-Mar. Inspiradas no plano de reforma do centro de Paris, idealizado pelo barão Haussmann, baseado na funcionalidade urbana para atendimento do fluxo viário pela abertura de vias amplas. Entretanto, essa reforma procurou atender os interesses da elite, pois a classe popular continuou a viver à margem das novas reformas, ou melhor, permaneceu ocupando os bairros velhos e socialmente estratificada. (Argan, 1993, p. 186) Este modelo serviu de inspiração para outros países, dentre eles o Brasil e mais especificamente o Rio de Janeiro. O mar, a praia e os parques urbanos foram alvos dessas mudanças, sob a introdução de um olhar que valorizava a natureza e perspectiva de ampliação. Essa redescoberta e valoração foram fenômenos muito importantes para a cidade, dentre outros que marcaram a busca pela construção de signos e referências para uma paisagem individualizada. Nesse processo urbanístico tanto a presença do bonde como transporte coletivo, como a iluminação pública também ampliaram as possibilidades da vida noturna e o início de novos hábitos domésticos de conservação de alimentos. (Lessa, 2001, pp. 198-205)

A configuração espaço-cultural da cidade decorrente das reformas trouxe em seu bojo a constituição e a preservação da ordem social, destinando grande parte do povo ao subúrbio, outros à subsistência nos prédios velhos no Centro da cidade e alguns mais à ocupação das encostas dos morros do Centro dando início ao processo de favelização. De acordo com Lessa (2001, p. 225), esse processo não apenas reduziu as possibilidades de mobilidade social das classes de baixa renda, como implicou na expansão desordenada do meio urbano do Rio de Janeiro e na precarização dos seus serviços. Vale notar ainda que durante as décadas douradas (1920-1960), em que pese a continuidade do projeto de fazer da cidade a representação do Brasil na modernidade, a ausência de uma industrialização plena acentuou as diferenças sociais inibindo ainda mais as possibilidades de mobilidade social.

Por ora cabe notar o que Lessa (2004) diz a respeito da relação da favela com o meio urbano do Rio de Janeiro:

No Rio de Janeiro, a urbanização sempre foi conservadora e tentou estratificar social e espacialmente a cidade. Na cidade Moderna, a segmentação residencial desenvolve os bairros; porém, necessita interarticulá-los, caso contrário, fracassa sua funcionalidade. (...) Entretanto, a topografia do Rio, as limitações do sistema de transportes e as características da demanda de serviços pessoais e de apoio às residências de renda mais elevada produziram a favelização associada, que avizinhou os estratos 
sociais da cidade (p. 15).

As reformas no cenário urbano prosseguiram após a Primeira Guerra Mundial ainda com o intuito de desconstrução da imagem do passado e busca pelo embelezamento da cidade. Sendo que essa nova paisagem agora deveria ser apresentada pelo orgulho da brasilidade, e não mais pelo paradigma europeu, o que culminou no Centenário da Independência em 1922 como um acontecimento de exibição do Brasil, através da Exposição Internacional. Esta, ocorreu na área de desmonte do Morro do Castelo na administração do prefeito Carlos Sampaio, e nesse lugar foram construídos edifícios que formaram os Pavilhões de exposição de cada país no evento. (Lessa, 2001, pp. 240-241) Cabe ressaltar que nesse momento a cidade passou a ser exaltada, com suas características e belezas próprias, deixando de ser o Rio Paris dos Trópicos, na entrada do século, para se constituir em Paraíso Tropical, em meados do século XX. Nesse momento o Rio também passou a investir na construção de sua identidade nacional de forma a dar visibilidade ao povo, antes invisível por não se enquadrar aos critérios civilizatórios. Assim, na cidade aberta, o carioca torna-se síntese ideológica de identificação do país, como um símbolo de incorporação dos tipos regionais, destacando-se pelas suas características ligadas a dinamicidade da própria cidade do Rio de Janeiro, representada nele através da improvisação interpessoal e pela capacidade de se "virar malandramente". (Lessa, 2001, pp. 246-263)

Ainda quanto à atitude da organização da Exposição Universal, Reis (2005, p. 11) destaca um contexto dual de exaltação das mudanças que marcaram de certa forma a inserção na modernidade, e por outro lado, as marcas ainda do atraso pela presença do povo miserável em condições bem diversas dos padrões da modernidade. O autor cita também sobre a nova geração que não foi aceita na Exposição e que originou o movimento modernista que mesmo com poucas possibilidades de se estabelecer, acreditou que em função da luta de classes acirrada em grande parte pela Revolução Russa de 1917, poderia fazer com que a burguesia buscasse uma outra posição que poderia levá-la a ruptura com os padrões conservadores "arcaicos", o que significaria romper com o padrão estético da Academia. Esta última, dominante na Exposição Universal pela elite conservadora. Mas, a incorporação pela burguesia da arte modernista se realizou como meio de assegurar o controle sobre a produção artística e não como uma absorção simples e ingênua do novo, pelo contrário, a burguesia não adere ou investe naquilo que de alguma forma não possa resultar em garantias para reprodução de sua ideologia. (Reis, 2005, p. 12)

Em síntese, as reformas urbanísticas empreendidas sob a administração de Pereira Passos e suas continuidades nos governos subseqüentes tinham como objetivo principal a ordenação da cidade a partir do planejamento urbanístico. Como vimos anteriormente, a construção da cidade moderna foi realizada sob a ótica do capitalismo mundial na medida em que buscou através das reformas a preservação da ordem social e a adequação espaço-cultural aos padrões de sociabilidade, sobretudo, provenientes das relações da organização industrial. A cidade passou a ganhar funcionalidades específicas para a 
demanda da produção industrial de forma a segmentar seu espaço habitacional pelo critério do nível social. Porém, a história da cidade mostra de alguma forma momentos de ruptura desses limites preestabelecidos, até mesmo provenientes da elite com o objetivo de garantir seu padrão social.

As reformas sempre visavam mostrar ao mundo que o Brasil estava civilizando-se, aderindo os padrões da modernidade e construindo sua identidade de Cidade Maravilhosa, enquanto cidade espetáculo para o mundo. Entretanto, tal processo se realizou de forma conservadora sob a demolição literal do passado que era identificado pelo atraso, mas com o agravante da estratificação social refletido no padrão de convivência pela configuração espacial dos bairros, a fim de assegurar os serviços prestados pela classe popular à elite. (Lessa, 2001, p. 235)

Por outro lado, a cidade passou a processar mais intensamente e de forma simultânea a produção cultural da classe popular característica de seus padrões de convivência cotidiana, sejam estes no interior de seu grupo social ou ainda pelas suas articulações com a elite, bem como a alta cultura com um repertório cultural significativo. Ambas produções construíram historicamente a identidade da cidade do Rio de Janeiro.

\section{O Rio Das Mudanças}

\section{Do Estado Novo À Ditadura Militar}

O contexto mundial a partir dos anos 30 foi marcado profundamente pela solução capitalista para crise engendrada pela Grande Depressão nos anos de 1929/30, através da constituição do keynesianismo e do regime fordista que em termos gerais significou a afirmação do Estado, sobretudo, na economia e nas políticas sociais. Tais medidas políticas e econômicas adotadas se consolidaram no período pós-guerra, entre 1945 até 1973, pela associação do keynesianismo ao fordismo como resultado de um acordo entre o Estado com o compromisso de assumir novos papéis, do capital corporativo, ajustandose a um ritmo de lucratividade, e do trabalho organizado, assumindo novos funções para 0 desempenho do mercado de trabalho da produção (Harvey, 1993, p. 125).

Em termos mais específicos, o fordismo foi um regime de acumulação com uma divisão do trabalho voltada para a promoção de lucros extremos sobre a produtividade. Isso se materializou pelo padrão de produção e consumo em massa, que também resultou na consolidação de um novo tipo de homem e de sociedade. O fordismo consistiu no regime de acumulação onde o poder corporativo de regulamentação pode constituir uma nova sociedade, com o controle através da pormenorização e disciplina do processo produtivo e ainda para o consumo em massa pelos trabalhadores. Para isso foi necessário a presença do Estado enquanto instância de intervenção social para garantir de forma eficaz tal reprodução capitalista. (Harvey, 1993, p. 122)

No âmbito das relações sociais, os papéis acordados entre o Estado e o Fordismo se desdobraram na vida existencial pelo desenvolvimento de uma atitude de adaptação do trabalhador ao sistema de trabalho fordista, pelo seu poder corporativista de investir e garantir o crescimento/estabilidade produtiva e ainda o próprio padrão de vida. Enquanto 
que ao Estado cabia garantir uma política fiscal e monetária voltada para o setor público que assegurasse o crescimento da produção e do consumo em massa e do emprego, bem como a complementação do salário social, garantindo os serviços básicos à população, e ainda sua presença nas negociações trabalhistas. (Harvey, 1993, p. 129) No contexto internacional, o fordismo também obteve progresso com a formação de mercados de massa globais e pela ampliação em massa da população para uma nova fase de acumulação capitalista. Cabe destacar que houveram diferenças nas formas de intervencionismo estatal nos países, mas o que marcou foi o crescimento econômico estável e o aumento do padrão material de vida pelo acordo entre o estado de bem-estar social, a administração econômica keynesiana e o controle das relações salariais. $O$ Estado tinha o papel de regulamentação social. Entretanto, mesmo os países tendo sua administração político-econômica particular estavam de alguma forma submetidos ao domínio dos EUA através das suas alianças militares e pelas relações de poder (Harvey, 1993, p. 131).

Os efeitos dessa solução no Brasil se realizaram a partir dos anos 30 com o início de um processo de ampliação da presença político-econômica do Estado Nacional de forma a reforçar sua centralidade. Nessa década, o Rio de Janeiro como capital do país se destacou pela centralidade do poder, ampliando-se cada vez mais como locus das questões públicas e culturais do Brasil. (Lessa, 2001, p. 268-270)

Foi também a partir desse momento que iniciou o processo de investimento na industrialização do país como meio de afirmação e progressão da questão social. Porém, cabe salientar que o Rio não liderou a produção industrial, mas foi lugar das relações de empreendimentos das grandes empresas, das transações financeiras e dos gastos públicos.

Já em 1937 foi instituído o Estado Novo que maximizou a centralização, destituindo os regionalismos estaduais e instaurando na capital federal a cúpula do regime ditatorial. Nesse momento foram realizadas ações para modernização e institucionalização do Estado em detrimento das oligarquias. (Lessa, 2001, p. 270)

No Estado Novo, tornou-se forte a convicção de que a industrialização e o trabalho proporcionariam a entrada do país na modernidade. O Rio foi o espaço de construção inicial das ações de afirmação do Estado através das políticas trabalhistas, previdenciárias e de assistência social do governo de Getúlio Vargas. Assim, as administrações municipais da cidade foram marcadas pelas ações de ampliação da cobertura das políticas sociais. (Lessa, 2001, p. 274-280)

A política governamental desenvolvimentista teve como foco principal a busca pelo desenvolvimento do país através de ações na área econômica e política, sob o investimento industrial. Já na segunda metade de 1950, sob o Plano de Metas JK, foi instalado todo um complexo industrial em São Paulo de forma a caracterizá-lo como epicentro industrial do país. No Rio de Janeiro o mesmo não se realizou completamente sob os padrões modernos da industria capitalista, identificamos quase que unicamente a 
construção naval com um desenvolvimento mais aproximado desses termos. Porém, tais diferenças, entre São Paulo e o Rio de Janeiro, dentre outras regionais não tornaram-se ao longo da história do Rio de Janeiro fatores dotados de força maior que pudessem impedir o seu desenvolvimento, pelo contrário, a cidade pelo seu caráter cosmopolita e nacional conseguiu processar bem as diferenças econômicas e culturais. (Lessa, 2001, pp. 345346)

Cabe também salientar no bojo da Segunda Revolução Industrial a presença do automóvel. No Rio de Janeiro, destacou-se ações para atender a demanda pela circulação automotiva em detrimento de medidas que pudessem priorizar o atendimento da população em termos sociais. Assim, a presença do automóvel na cidade é marcante, principalmente, no século XX como representação da modernidade, o que se tornou alvo de consumo e exibição. Na medida em houve o aumento da frota e da circulação do auto na cidade, ações de investimento na engenharia de trânsito procuraram expandir a rede viária pela construção de vias expressa, túneis, viadutos, pistas com mão única, etc., de forma a adaptar a cidade ao automóvel. Os padrões e hábitos cariocas também foram alvo de modificações a partir do auto, criando novos padrões de comercialização, como o supermercado, o shopping e outros, o que implicou no desinteresse pelas atividades ao ar livre proporcionadas pelo passeio na calçada ou pelo bulevar. (Lessa, pp. 362-365) Após as décadas douradas (1920-1960), o Rio sofreu progressivamente a perda de seu prestígio político pela transferência da capital para Brasília em 1960, o que deu início a um processo de certo esvaziamento à cidade. Foi também em 1960 que o Distrito Federal passou a ser estado da Federação, tendo a cidade/estado da Guanabara subsistido sob três governos até 1975, quando o governo autoritário realizou a fusão da Guanabara com o Rio de Janeiro, limitando a cidade do Rio cada vez mais aos poderes de município. (Lessa, 2001, p. 345)

A partir de 1960 propôs-se o desenvolvimento para a Guanabara pela industrialização, sobretudo, pela constatação do atraso do Rio de Janeiro em relação a São Paulo. Nesse sentido, após a Segunda Guerra Mundial acentuou os investimentos para uma política industrial no Rio que até os anos 70 procurou dinamizar a instalação de distritos industriais, entretanto, como já foi salientado, na cidade do Rio não foi consolidado um sistema industrial sob os padrões capitalistas que pudessem caracterizar um pleno desenvolvimento industrial. Já sob o governo Geisel, com o II Plano Nacional Desenvolvimentista (PND), realizou-se a fusão da Guanabara com o Rio de Janeiro de forma autoritária e destinou ao mesmo a localização de pólo industrial e de atividades tecnológicas de ponta, originando a instalação de novas industrias e o reforço das já existentes, bem como o desenvolvimento nacional de pesquisas científicas e tecnológicas na cidade. (Lessa, 2001, pp. 347-349)

Nos anos 80, tornou-se visível as medidas fracassadas de industrialização, seja pela perda de unidades industriais e transferência em grande parte para São Paulo, seja também pelo processo de transferência da capital para Brasília, resultando numa série de perdas 
recorrentes até os dias atuais, sobretudo, em termos econômicos. (Lessa, 2001, p. 351) O declínio do Rio pela perda de seu prestígio enquanto capital se processou de forma bem diferente da esperada pelo carioca, ou seja, daquela que poderia se realizar de forma progressiva e sem deixar maiores prejuízos. Sob o regime autoritário a partir de 1964, ocorreu a transferência quase que imediata do quadro superior administrativo e posterior a 1968, de todo o aparato burocrático. Entretanto, a esfera federal continuou proprietária da maior parte do espaço urbano do Rio, mas que ao longo dos anos mostrou seu total relapso na preservação de seu patrimônio. Nesse processo, a cidade foi perdendo também no imaginário social a sua auto-estima e identidade brasileira. (Lessa, 2001, pp. 356-357) A transição da capital do Rio de Janeiro para Brasília pode ser comparável em certa medida com a Reforma Pereira Passos no Rio, como Lessa (2001, p. 398) destaca curiosamente, pelo fato que a proposta do Plano Piloto de Brasília também teve como alvo o futuro, porém ambas não conseguiram alcançar de forma plena tal objetivo por se realizarem de forma autoritária. Ambas trouxeram consigo a estratificação social, a primeira dando início ao processo de favelização e a segunda às cidades-satélites, onde percebemos facilmente que em seu planejamento o povo não estava presente.

\section{A abertura política e a reforma do Estado}

O período de 1965 a 1973 foi o momento em que o fordismo e o keynesianismo começam a se defrontar com as contradições do próprio capitalismo. Os paradigmas baseados na rigidez de investimentos e planejamento de forma a propor mercado e consumo como invariáveis, passam a ter dificuldades diversas pela falta de flexibilidade. Isso porque iniciava-se um contexto que propunha mudanças nesses padrões rígidos, quando mais tarde viriam a se consolidar através de um regime econômico e político a partir de fundamentos flexíveis. Mas, o que apenas podia ser considerado flexível no padrão de acumulação fordista foi a política monetária que pelo excesso de fundos produziu forte inflação. (Harvey, 1993, pp. 135-136)

A partir dos anos 70 as corporações entraram num período de racionalização, com mudanças tecnológicas e a reestruturação das relações de trabalho a partir da deflação de 1973 que junto ao choque do petróleo contribuíram para a formação de um novo regime de acumulação pelo capitalismo.

A acumulação flexível foi a nova estratégia de acumulação que trouxe transformações nas bases produtivas, bem como nas relações políticas e sociais. Assim, novos paradigmas flexíveis implicaram em mudanças nas relações de trabalho e de produção, como nos mercados e também nos padrões de consumo. Esse novo regime criou setores vastos de empregos na prestação de serviços e sistemas de produção em áreas geográficas distintas, mas sob um controle mais forte do trabalho através das novas possibilidades quase imediatas de tomadas de decisões, proporcionadas pela tecnologia de comunicação que permitiram o acesso a diversos espaços em tempo real. (Harvey, 1993, p. 140) O mercado de trabalho também sofreu mudanças significativas na medida em que diminuiu os postos de trabalho formais com tempo integral e as carreiras profissionais com 
maior segurança mediante a garantia de direitos já adquiridos pela classe trabalhadora, e em contrapartida, aumentou do trabalho parcial, temporal ou sub contrato. Este último, com menos segurança em função da rotatividade proveniente dos paradigmas da flexibilidade, como também pela diminuição dos direitos, o que fez reduzir os custos com demissão. No bojo dessas mudanças, houve um grande aumento dos índices de desemprego que passaram a ser estruturais, bem como a diminuição do poder sindical. Esse processo gerado, sobretudo, por um movimento de exclusão do mercado formal de trabalho, resultou no reaparecimento de atividades informais ligadas ao trabalho doméstico, artesanal e familiar que passaram a ocupar não mais uma posição secundária de suplemento ao sistema produtivo, mas tornou-se inerente a lógica atual do sistema capitalista. A formação de novas atividades informais, bem como o reaparecimento de formas antigas passaram a demarcar a busca pela sobrevivência para os desempregados ou até como meio de sonegação fiscal, principalmente, pelo comércio ilegal para inserção no sistema capitalista. (Harvey, 1993, pp. 143-145)

O sistema produtivo em si diferiu da produção fordista pelo atendimento ao mercado com produtos fabricados em pequenos lotes em função da constante inovação do produto em detrimento da produção e do consumo anterior em larga escala. Isso porque novos padrões de consumo se estabeleceram baseados em necessidades efêmera e de destaque da diferença em que requer para si a personalização dos produtos. O tempo de vida do produto diminuiu pelo consumo e tempo acelerado, o que Harvey (1993, p. 148) destaca como "aceleração do tempo de giro na produção", em virtude da diminuição "do tempo de giro no consumo".

Apesar do caráter flexível pela capacidade de mobilidade geográfica produtiva em que as corporações coordenam produtores independentes em áreas diversas e que posteriormente tem seus produtos aglomerados, identificamos que o capitalismo sob esse novo tipo de regime se torna cada vez mais organizado de forma a obter maior controle pela tecnologia da informação. Esta tem propiciado também a expansão de serviços de consultoria ligados a capacidade de fornecer em tempo imediato informações sobre o mercado e dados relativos as ações das corporações. (Harvey, 1993, p. 150-151) Como vemos, as corporações se modificam de acordo com a demanda desse novo contexto em que traz consigo formas de reorganização do sistema capitalista para que possa garantir sua reprodução e hegemonia. Novas estratégias são sempre apresentadas às corporações para sua inserção na batalha competitiva, como o investimento no marketing empresarial, nos patrocínios e parcerias com setores públicos e privados, formando as famosas Parcerias Público Privado (PPP), dentre outros mecanismos para assegurar espaço no mercado. (Harvey, 1993, p. 152)

Algumas mudanças também ocorreram no campo do poder político na medida em que houve um fortalecimento do capital financeiro e a diminuição do poder do Estado. Nesse sentido, o poder do Estado é uma das questões centrais da acumulação flexível pela lugar em que passou a ocupar, sobretudo, nas relações entre o patronato e os trabalhadores. $O$ 
Estado deixou de estar na vértice da pirâmide, dando lugar as grandes corporações que passaram na maior parte das vezes a administrar as relações entre estas, o Estado e os trabalhadores. A retirada do estado de bem-estar social foi uma estratégia para enfrentar a crise de 1973-1975, no fim do fordismo, enfraquecendo o trabalho organizado e o movimento sindical, mas buscando favorecer os negócios e criando instituições de controle como o Fundo Mundial Internacional (FMI) e o Banco Mundial (BM). Em síntese, hoje o Estado vive um paradoxo, pois ao mesmo tempo tem o papel de defender o capital nacional corporativo, como também manter relações amistosas no mundo global dos negócios a fim de atrair capital financeiro. (Harvey, 1993, pp. 158-160)

O Brasil, nos últimos anos, foi atingido pelo discurso da globalização e pelo ideário do Estado Mínimo, onde a inserção do país no contexto mundial competitivo se tornou um dos objetivos maiores do governo em detrimento do desenvolvimento de um projeto nacional. Os resultados disso podem ser identificados pela submissão aos fatores econômicos e políticos do mercado mundial, bem como a atuação de órgãos multilaterais em nosso país intervindo na política governamental como um todo. Ao mesmo tempo, a população sofre com as conseqüências dessa nova fase de acumulação capitalista, sobretudo, pela crise do desemprego, pela estagnação inflacionária, pelas privatizações e pela perda dos direitos de proteção social antes garantidos de certa forma pelo Estado.

Na década de 90, houve uma significativa redução de empregos formais qualificados, atingindo em cheio a classe média. No Rio não foi diferente, a classe média carioca vivenciou esses efeitos tanto pelo declínio da burocracia pública quanto privada, o que resultou no rebaixamento dos postos de trabalho e renda. A partir da desestabilização dessa classe, novas formas de relacionamentos foram travadas entre esta, sobretudo, os seus segmentos mais precários, e a classe popular como saída para garantir sua própria existência. Ambas passaram a estabelecer uma relação de aprendizado, pois ao procurar junto ao popular meios de assegurar sua subsistência, esta também pode fornece-lhes subsídios para luta política, visto que a classe média tem como diferencial na sua história uma certa experiência de cidadania pela garantia e acesso aos direitos sociais. Através desta troca, pode-se deduzir possibilidades do povo junto a classe média lutar pelos seus interesses em busca da garantia de seus direitos (Lessa, 2001, pp. 435-442).

O Rio de Janeiro vive da mesma forma essa crise pelo discurso da decadência e pela violência na cidade. Mas, o carioca de alguma forma não desistiu e buscou mais uma vez alguma saída para tais problemas da mesma forma que buscou reverter seus problemas no século XIX com a reformulação da cidade para inserção no contexto da modernidade. Mais recentemente, o meio de superação pelo qual o carioca, com o sentimento de decadência, encontrou para inserção na pós-modernidade foi através da construção do espaço urbano da Barra da Tijuca. Este atualmente tornou-se representação dos padrões pós-modernos pela elite, que Lessa destaca ironicamente (2001, pp. 410-411) como a busca pela reprodução kitsch de Miami no Rio de Janeiro. A Barra além de ser pósmoderna pela presença de seus padrões urbanísticos e consumistas, também foi 
transformada em um espaço que combinou a necessidade de segurança pela elite frente a violência na cidade. É possível identificar isso pela presença nos condomínios de segurança privada, entre outros mecanismos de segurança, como o veículo blindado, e também pelas formas de convívio em espaços fechados como o shopping (Lessa, 2001, pp. 395-407).

O carioca diante da violência perde o seu padrão de cordial e alguns de seus ícones ligados ao Paraíso Tropical, passando a ser sufocado pela realidade da exclusão social, do desemprego e da violência. Assim, o Rio vai progressivamente nas últimas décadas perdendo toda representação construída no cenário brasileiro, a favela é exemplo disso, pois na medida em que perde a sua imagem romantizada, passa a ser banalizada por se multiplicar de forma indiscriminadamente. Hoje a cidade carrega consigo o estigma da violência e a favela tornou-se locus dessa representação, principalmente pela presença do crime organizado de forma a homogeneizar todo habitante da favela como integrante deste ou do narcotráfico (Lessa, 2001, p. 418).

Porém, mesmo em meio aos problemas que o carioca enfrenta atualmente na cidade, ele não deixou de lado sua característica cultural construída ao longo de sua história que é a capacidade criativa da classe popular. O carioca aderiu os padrões modernos e agora também aos pós-modernos de um jeito peculiar em que a sua criatividade permite dar um sentido quase que próprio a determinados usos e fins, atendendo a sua demanda simbólica. O povo do Rio faz de sua cidade um espaço de identificação cosmopolita, aberto a todo tipo de influências e gostos, sem abdicar de seu poder (re)criador (Lessa, 2001, p. 425).

O Rio de Janeiro viveu alguns dos efeitos da globalização quase que prematuramente, sobretudo, pela transferência político-administrativa para Brasília. Na verdade, o processo ocorrido nos últimos tempos em relação a globalização tem sido uma continuidade de mudanças já iniciadas anteriormente quando a cidade deixou de ser capital. Os padrões que atualmente tem sido incorporado nas áreas industriais, como a terceirização de serviços, já faz parte do passado do Rio. O povo da cidade já tem uma história ligada a "não-especialização" (Lessa, 2001, p. 432) na medida em que desenvolveu formas flexíveis de trabalho e sobrevivência ligados à logística urbana e a prestação de serviços domiciliares.

\section{O TRABALHO}

\section{Formal}

O movimento da classe dos trabalhadores formais industriais do Rio de janeiro evoca o resgate especialmente da classe metalúrgica pelo lugar que historicamente ocupou no cenário de mobilização em torno da construção de sua identidade política e social. A experiência da classe trabalhadora carioca foi marcada por um movimento peculiar de alianças em sua composição, com a participação de autoridades políticas em função da proximidade física com estas, já que o Rio de Janeiro era capital do país. Nesse sentido, 
articulou-se também com a lógica do governo populista de Getúlio Vargas em seu projeto corporativista, onde se destacaram os trabalhadores das empresas estatais que de alguma forma representaram uma ação sindical de resistência no período pós-64 (Pessanha, 1994, p. 14).

O período populista foi marcado por uma intensa articulação política para o desenvolvimento da identidade coletiva dos trabalhadores da indústria naval do Rio de Janeiro, pelas conquistas políticas e socais que marcaram "a época dos operários navais", o que caracterizou no imaginário desta categoria uma geração ativa no movimento sindical que buscava a garantia de seus direitos, benefícios e participação no cenário político. Mas, esse quadro satisfatório aos trabalhadores da época mudou em função do golpe militar de 1964, redefinindo os operários navais em metalúrgicos, o que resultou na inserção sindical nesta última categoria pela resistência às condições adversas do autoritarismo político, da modernização, da racionalização do processo de trabalho e da crise econômica dos anos 80 (Pessanha, 1994, pp. 18-27). Essa experiência apontou para o destaque da construção da identidade dessa classe sob o processo de descontinuidades, vivenciadas pelos operários navais pelo significativo rompimento de sua inserção política e de sua relação com o Estado, como também de continuidades, através da socialização da memória de lutas políticas, profissionais e sindicais desses operários.

A classe trabalhadora do Rio de Janeiro passou por experiências também sobre as formas de gestão das empresas estatais, marcadas pelo caráter ideológico corporativista e disciplinar do Estado Novo que se alongava, principalmente, a absorver os conflitos de classe, como o controle dos trabalhadores estendido à esfera da vida social. A presença sindical nessas empresas teve que lidar com a situação ora de contestar o estado ora de apoiá-lo como agente político, porém a institucionalização do sindicato foi importante na construção da identidade desse grupo. No conjunto dessas relações, a Fábrica Nacional de Motores (FNM) marcou um movimento pelos trabalhadores frente aos padrões de dominação que se caracterizou pela resistência individual ou coletiva tanto no processo de trabalho quanto na participação política sindical, suas particularidades advêm das ações políticas sindicais que objetivavam uma luta de classe mais geral, enquanto que os trabalhadores mais antigos procuravam se constituírem como uma classe em torno apenas dos seus embates mais cotidianos. Embora essa complexidade na resistência operária, ela não se desqualificou frente a reação às formas de dominação impostas.

A Companhia Siderúrgica Nacional (CSN) também traz uma exemplificação acerca do caráter de gestão paternalística que de certa forma aparece na história de seus trabalhadores caracterizando suas benesses, bem como na memória de uma linguagem política em torno da consciência da exploração através de um sentimento de injustiça. Os estudos organizados por Abreu e Pessanha (1994), também trazem os movimentos mais recentes em torno da segregação do mercado de trabalho a partir da categoria de gênero, mostrando assim, a inserção da mulher nos diferentes modelos ocupacionais urbanos. A trajetória histórica articula-se ao contexto cultural-econômico identificado desde 
da inserção da mulher de forma significativa na passagem do século XIX para o XX, à racionalização feminina no período entre 1920-1950 e a flexibilização nas fronteiras de sexo no período de 1950-1980, que mesmo assim, mostra a tradição ocupacional feminina. As ideologias de gênero trazem até desdobramentos nas relações de sub contratação no setor de confecção do Rio de Janeiro, influenciando a inserção de costureiras e alfaiates no mercado de trabalho e nas oportunidades de desenvolvimento profissional.

\section{Informal}

O trabalho livre a ser abordado é o personagem que Lessa (2001), ao apontar o panorama sociocultural da cidade do Rio de Janeiro através de sua história, traz em destaque com presença essencial na classe popular ligada a atividade de prestação de serviços a partir do século XIX, com sua origem ligada a escravidão e ao trabalho logístico urbano. O autor observa que o avanço do desenvolvimento industrial no século XIX, no Rio de Janeiro, se realizou sem destituir o artesão e, ainda mostra, como o padrão da família rural - com a utilização do trabalho escravo - influenciou para que não houvesse efetivamente uma divisão entre o escravo de ganho e o grande número de homens e mulheres livres e pobres prestando serviços domésticos e domiciliares, como também as atividades logísticas e o artesanato. Porém, no final do século XIX, o processo de industrialização no Rio de Janeiro não se efetivou completamente, o que impulsionou essas características para o século XX.

O crescimento da cidade trouxe consigo o problema da delimitação entre o público e o privado, isso em grande parte em função da ampliação da escravaria doméstica e também da multiplicação de escravos ligados à prestação de serviços logísticos. No espaço urbano, ambos passaram a transitar pelo espaço público e travaram possibilidades de contato com outros populares livres e libertos. O prestador de serviço buscou residir próximo do mercado de trabalho e o escravo doméstico, na cidade, tornou-se "propriedade particular móvel" (Lessa, 2001, p. 78), transitando nas ruas.

Já no século XVIII a cidade recebe o título de capital e, como já exposto anteriormente, inicia um processo de formação política, econômica e cultural da cidade do Rio de Janeiro. A institucionalização do aparelho estatal e o poder público passaram por uma dinâmica de articulação do aparelho burocrático com um sistema clientelista.

A população livre e pobre procura se aproximar do centro buscando possibilidades de integração com a elite da capital pelos seus serviços residentes e a logística de comercialização urbana. Desde desse período, nota-se na cidade a articulação da elite com a base social, sobretudo, no que Lessa destaca pela

[...] circulação de seus escravos domésticos e contatos com os homens livres e pobres, seus prestadores de serviço. O caldeirão urbano processa estes dados fortemente diferenciados e surpreendentemente próximos (2001, p. 93).

Sob o contexto que estamos refletindo de inserção na modernidade, século $X X$, podemos identificar que as reformas urbanas já supracitadas na República Velha trouxeram consigo as estratificações sociais e mesmo durante as décadas douradas (1920-1960), sob as 
realizações em torno do desenvolvimento industrial, as diferenças sociais continuaram a existir com grande parte da população num padrão inferior de vida. Esse processo não apenas reduziu as possibilidades de mobilidade social das classes de baixa renda, como implicou na expansão desordenada do meio urbano do Rio de Janeiro e na precarização dos seus serviços.

Muito embora a modernização da cidade do Rio de Janeiro tenha se realizado sobre um processo de estratificação social, o intuito civilizatório progressista da classe dominante só poderia se efetivar através da mão-de-obra barata proveniente das classes de baixa renda. Nesse sentido, seja pela necessidade logística da prestação de serviços seja pela proximidade do mercado de trabalho, o povo pobre passou a ocupar os morros criando formas de sobrevivência com características próprias de regulação e formas criativas de reparação de objetos industriais.

Portanto, é de se notar que o crescimento das favelas tem acompanhado a dinâmica dos bairros e da logística do comércio urbano em função da demanda pelos serviços prestados pelo habitante da favela. De outra forma, na medida da existência de um mercado de trabalho em permanente expansão, a busca de redução de custos de transportes e moradia levou a favela a construir o seu próprio espaço de sobrevivência, guiando-se por padrões de regulação distintos da cidade. É nesse sentido que se observa o desenvolvimento de um tipo de trabalho de reparação ou reciclagem de artefatos industriais de toda ordem (de móveis a utensílios domésticos, de eletrodomésticos até automóveis).

Segundo Lessa (2001) e Reis (2003-2004), o processo de modernização da cidade não se realizou sobre um processo de inserção industrial, e sim, sobre a presença do artefato industrial e seu destaque na mídia, o que resultou na formação de profissões paraindustriais. Atividades ligadas a "reciclagem" desses objetos de forma a dar-lhes sobrevida se articulam ao imaginário do povo carioca na busca de sua inserção no processo de modernização, criando uma tradição carioca criativa para atender a demanda da população. Assim, surgem profissões características de trabalhadores pobres na cidade decorrente da submissão aos fatores socioeconômicos e culturais no campo simbólico que, por outro lado, aponta para um sentimento característico de criatividade e extroversão.

Esses trabalhadores "recicladores" de alguma forma reproduziam aspectos ideológicos, como a hipótese de propriedade de seu próprio negócio, mas diferentemente das estruturas históricas do trabalho capitalista, ele criou formas flexíveis de trabalho e sobrevivência fora dos moldes da especialização.

Por último, cabe também destacar nesse contexto, o papel do trabalhador negro livre, cuja trajetória de ocupação na cidade se confunde com a da população pobre do subúrbio, da periferia e da favela. Submetido a uma condição precária de vida e ao preconceito racial, o trabalhador negro livre ocupou posições secundárias no mercado de trabalho, caracterizado pelo subemprego em ofícios ligados a prestação de serviços e ao comércio 
ambulante de frutas, vísceras de animais e pescado. Sua aprendizagem dos ofícios artesanais se dava através de um familiar mais antigo ou pelo grupo social (Moura, 1995, p. 69/70).

\section{O trabalhador na rua}

Pretendemos agora descrever e analisar as características gerais do trabalho realizado pelo "reciclador" de artefatos industriais nas ruas do Rio de Janeiro, cuja presença singular no universo das "profissões" urbanas atravessa todos os períodos da história moderna da cidade. Da mesma forma, a partir da pesquisa empírica que realizamos junto a estes trabalhadores sobre a sua formação e hábitos culturais, buscaremos apreender e entender o lugar simbólico ocupado por eles no contexto cultural da cidade, considerando o aspecto macroeconômico e político, os investimentos públicos e privados no setor.

Para tanto, resgatamos o contexto dos anos 90, quando o Brasil foi atingido pela nova ordem global caracterizada pelo regime de acumulação flexível. A adequação do país aos paradigmas da flexibilidade, forçou-o a adotar políticas neoliberais que já inicialmente resultaram em uma crise estrutural de desemprego. No bojo destas políticas, associou-se um processo de privatizações e perda dos direitos de proteção social antes garantidos de certa forma pelo Estado. Para Tiriba (2001, pp. 339-372), a crise do desemprego pela exclusão no mercado formal oriunda da reestruturação produtiva, trouxe consigo velhas formas de trabalho. Nesse sentido, a autora expõe a intensificação de uma economia solidária com uma produção associada que apresenta diferentes identidades, mas que em grande parte é impedida de se tornar um projeto hegemônico popular. Tal apontamento se justifica pela constatação de algumas produções associadas se encontrarem ligadas aos interesses do capital e outras voltadas para a sobrevivência dos setores populares e o estabelecimento de novas relações neste setor. Mas, o foco, sobretudo, está nas formas de reprodução ampliada da vida como resultantes do processo de exclusão social, ou seja, nas organizações econômicas populares alternativas aos trabalhadores excluídos do trabalho formal assalariado, com uma divisão de trabalho menos rígida e hierarquizada. $\mathrm{Na}$ verdade, são mediações frente às condições concretas em que o próprio capital expõe as classes populares. Elementos esses que nos apontam ser conflitantes com a lógica dominante de produção capitalista.

Desta forma, a solidariedade que a autora aponta está presente nas relações dos setores populares através de ações coletivas de cooperação material e imaterial na busca de garantir suas condições de sobrevivência. As experiências com os vínculos de solidariedade são vividas a partir do momento em que há cumplicidade entre os sujeitos envolvidos. Como também, os objetivos da ação coletiva podem estar ligados à defesa dos direitos fundamentais do indivíduo ou com a necessidade imediata da vida. A autora pensa a solidariedade nesse contexto como algo alternativo à lógica do capital. Portanto, a economia solidária pode significa para uns apenas meio de sobrevivência, como que para outros o estabelecimento de relações com a comunidade. Mas, sob o contexto já apresentado, constatamos que a economia solidária em sua totalidade é exercida em 
primeiro lugar em torno da satisfação das necessidades básicas de sobrevivência para que, posteriormente, possa se configurar em desdobramentos ligados à constituição de uma forma de organização economicamente viável e de participação no projeto de transformação social. Entretanto, sabemos que as organizações de economia solidária são frágeis economicamente no sentido de que não conseguem suprir todas as necessidades básicas dos sujeitos, bem como garantir uma qualidade de vida plena para além das necessidades biológicas. (2001, pp. 352-366)

A autora nos aponta ainda que nas organizações econômicas populares busca-se a retomada do trabalho criativo, o que não impede o acesso às tecnologias desenvolvidas que se encontram sob o domínio da classe dominante. No entanto, cabe esclarecer que essa apropriação não deveria se realizar como reprodução das relações sociais estabelecidas pela produção capitalista no uso destas (Tiriba, 2001, p. 367) Vemos então que a crise estrutural do desemprego impôs aos diferentes segmentos das classes mudanças no padrão de consumo e também nas relações sociais de produção. Assim, a tradicional forma que o carioca tinha de lidar com os artefatos industriais se intensifica, levando-o a reciclar um número bem maior de móveis, utensílios domésticos, eletrodomésticos e até automóveis, bem como observamos este fenômeno articulado às transformações nas relações sociais de produção que levaram a uma intensificação de uma economia solidária que, por conseguinte, consolidou este trabalho de reparação ou reciclagem de artefatos industriais de toda ordem.

A partir da presença desses trabalhadores, exercendo em grande parte atividades industriais ou semi-industriais, mesclando conhecimento técnico-científico com habilidade artesanal, que se nota um imenso caldeirão de culturas, em parte associada ao desenvolvimento industrial em parte a manufatura, na qual se molda a variedade de tipos e expressões artísticas características da paisagem cultural do Rio de Janeiro.

\section{A formação estético-cultural do "reciclador" - alguns dados da pesquisa empírica}

A pesquisa de campo foi realizada nos anos de 2003 e 2004 com os trabalhadores "recicladores" de artefatos industriais e/ou manufaturados localizados em pontos/estabelecimentos nas ruas da cidade do Rio de Janeiro, na zona sul, norte e centro [1]. O procedimento metodológico adotado consistiu de entrevistas estruturadas mediante as quais preenchíamos um formulário dividido em três partes. Foram realizadas um total de 25 entrevistas.

Na primeira parte foram registrados o nome, a idade e a naturalidade do trabalhador. Ainda nesta parte, foram levantados os dados relativos à localização/zona geográfica da cidade do ponto onde o trabalhador exerce o ofício, o tempo de ocupação do ponto, a freqüência e a carga horária de trabalho.

Na segunda parte, considerando as características do zoneamento/localização do ponto de trabalho, foram levantados os 10 ofícios mais comuns da cidade do Rio de Janeiro. Agregado a esse levantamento verificou-se o tempo de ofício, a existência de algum tipo de aprendizado, a existência de algum tipo de formação profissional, a existência de algum 
tipo de outra ocupação e a escolaridade do trabalhador.

$\mathrm{Na}$ última parte, foram levantados os hábitos culturais do trabalhador, considerados quanto à atividade de lazer, a diversão/entretenimento preferido, a freqüência dessa atividade e a algum tipo de formação artística.

A pesquisa revelou que o trabalhador/reciclador tem, em média, 45 anos. Em sua significativa maioria esse trabalhador é carioca, exerce o seu ofício, em média, há 20 anos, trabalhando em tempo integral há mais de dez anos no mesmo ponto. Pouco menos da metade deles aprendeu o ofício "na prática" com um "mestre oficial", sendo este o dono do negócio e/ou um membro da família. Da mesma forma, um pouco menos da metade restante declarou ter tido algum tipo de formação profissional relativa ao ofício exercido, no Senai, Senac e/ou em pequenas escolas de formação profissional. Mais da metade dos trabalhadores declarou não ter outra ocupação além do ofício exercido. Quanto à escolaridade desses trabalhadores/recicladores, verificou-se que a média de anos freqüentados na escola é de 7,8 anos.

Já quanto os aspectos culturais a pesquisa considerou a atividade de lazer em associação com a preferência por algum tipo de diversão/entretenimento. Complementarmente, buscou saber junto aos trabalhadores/recicladores a existência de algum tipo de formação artística.

Dentre os 25 entrevistados, quatro declararam ter formação artística, sendo relacionadas artes plásticas, teatro e música.De todo modo, podemos ressaltar nesta reflexão como o ensino de artes tem se realizado nas escolas, sobretudo, por ser um componente curricular que objetivamente pretende propiciar mecanismos em torno do conhecimento estético e de sua fruição. Chegamos a questionar até que ponto o ensino de arte tem se pautado unicamente na contemplação de "gênios" da arte sem relativizar o processo da produção de um bem artístico e seus aspectos históricos e sociais. Ou então, se tem implicitamente servido à reprodução da mercantilização da produção cultural pela via da publicização da produção em si para o consumo em massa.

Os dados coletados nas entrevistas com os trabalhadores indicam percentuais desprezíveis de trabalhadores frequentadores de espaços e eventos culturais públicos, porém quase nunca gratuitos. Isto porque, conforme levantamento que realizamos acerca dos investimentos públicos e privados em atividades culturais na cidade do Rio de Janeiro, apreendidos como políticas públicas das esferas municipal, estadual, federal e privadas (2002-2004), a quase totalidade deles concentram-se na zona sul da cidade, área de grande densidade de famílias das classes abastadas, o que por si só constitui um fator inibitivo do acesso do trabalhador a esses espaços e eventos. Por outro lado, a distância, considerando o custo de transporte para uma família, constitui outro fator impeditivo do acesso por parte dos trabalhadores aos espaços culturais e aos eventos.

Estar em casa junto à família "assistindo à TV ou vídeo", "lendo jornal, revista ou livro" revelou ser a atividade de lazer/diversão/entretenimento preferida da expressiva maioria dos entrevistados. Dentre as atividades realizadas ao ar livre, "jogar futebol", "passear" e "ir 
à praia", foram relacionadas dentre as preferidas. Outras atividades realizadas fora de casa, mas em ambientes fechados, também foram relacionadas, sendo "ir à igreja", "beber em bar", "ir ao cinema", "ir a museu/galeria de arte" e "ir a espetáculo musical". Contudo, o traço de união de todas as respostas é, sem dúvida, a endogenia, caracterizada pela vida comunitária.

Contrariamente ao que ocorre nas áreas predominantemente marcadas pela presença das classes abastadas, nota-se nos espaços populares a ausência de qualquer investimento público ou privado no sentido de dotá-los de recursos para a preservação do patrimônio histórico e equipamentos culturais, como museus, centros culturais, exposições e projetos culturais, restringindo-se, em alguns bairros da periferia e favelas a instalação de lonas culturais e bibliotecas volantes.

Se pensarmos melhor esta questão, relacionada, por exemplo, ao quantitativo de residentes nas áreas ocupadas pelas classes de baixa renda na cidade do Rio de Janeiro, logo percebemos como as ações culturais nesses espaços são precárias e em total desacordo com este dado, pois, em diversas áreas da cidade, a favela possui muito mais residentes do que nos espaços ocupados pelas classes abastadas. De acordo com a lógica distributiva brasileira, segundo a qual muitos não têm nada e poucos têm tudo, também na esfera cultural prevalece essa idéia. Um exemplo notável disso situa-se na Linha Vermelha, porta de entrada da cidade para quem chega do exterior de avião. Lá, nas 12 comunidades faveladas da área da Maré, um complexo onde 132 mil trabalhadores se espremem numa estreita faixa de terra entre a Av. Brasil e o lodo fétido da baía de Guanabara, as ações culturais do poder público são inexpressivas, enquanto que na Barra da Tijuca a prefeitura enterra 150 milhões de reais na construção de uma duvidosa cidade da música. Mais adiante, no próximo estudo, voltaremos a este assunto.

\section{A CULTURA}

A análise das políticas culturais colocadas em prática no Rio de Janeiro no período aqui estudado, pressupõe o entendimento do conceito de fetichismo da mercadoria (Marx) ou reificação (Lukács). A importância do estudo deste conceito, nos limites deste trabalho, prende-se à necessidade de melhor avaliarmos a relação entre a produção cultural e a dominação econômica. Nesse sentido, a compreensão do conceito nos auxiliará na avaliação do valor atribuído pela classe dominante, seja através do poder público seja diretamente através de investimentos privados seja pela seleção exercida pelos meios de comunicação[1], aos produtos culturais.

\section{Fetichismo e reificação - notas teórico-metodológicas sobre a questão cultural}

Marx ao analisar o valor designou o conceito de fetichismo da mercadoria como uma decorrência do caráter social do trabalho ao produzir a mercadoria (lanni, 1985, p. 161).

Mais tarde, Lukács, estudando o fetichismo da mercadoria, elaboraria a teoria da reificação. (Goldmann, 1979, p. 109). De acordo com Lukács, através desta teoria é possível melhor compreender as relações entre a estrutura e a superestrutura. 
Para melhor clarificar a questão é necessário entender o conceito de valor por ser basicamente o fundamento da dinâmica capitalista. $O$ valor é baseado na relação social entre as pessoas e assume como forma material específica a mercadoria. No que tange ao valor de troca da mercadoria, podemos afirmar que esta é sem distinção produto do trabalho, caracterizado nesse sentido como trabalho abstrato pelo seu caráter de homogeneidade. Sendo assim, o valor é quando este trabalho abstrato se torna objetivo, o que é medido de acordo com uma média de tempo socialmente necessária para produção da mercadoria. O que nos mostra que o valor não é proporcional ao que o trabalho concreto produz, mas à quantidade de trabalho abstrato que se objetivou na mercadoria. (Bottomore, 2001, pp. 397-400)

Dessa forma, o capitalismo inverte as relações sociais de produção na medida em que através da aparência falseia a realidade objetiva. Marx complementa esta análise apontando de que modo tais inversões refletem na consciência.

Para ele, no modo de produção capitalista, as relações sociais são marcadas pelas relações entre mercadorias, ocultando, desse modo, as relações entre os indivíduos (produtores/consumidores). Marx denominaria este efeito de ocultamento como fetiche da mercadoria. Esse conceito é base para compreensão da influência do capitalismo nas relações não-econômicas e na relação dicotômica entre aparência e realidade objetiva (Bottomore, 2001, p. 150).

A teoria marxista, ao buscar estabelecer uma reflexão pautada na totalidade da realidade, destaca como a questão econômica (a estrutura), na medida em que estiveram primordialmente voltadas para produção e a distribuição material, é um fato real que historicamente teve primazia nas relações humanas. Goldmann (1979, p. 11), aponta que o fator econômico preponderou sobre o pensamento e o comportamento do homem de modo que o fator quantitativo passou a ter representação em outros campos da vida social em detrimento do fator qualitativo ligado estritamente as relações humanas. Assim, o autor destaca que a consciência na sociedade capitalista clássica perde seu caráter ativo para se tornar somente passiva e reflexa do processo de reificação que está presente no campo do pensamento e da afetividade. Sob essa realidade, todas as manifestações da vida foram apoderadas pelo conjunto econômico, por isso, a necessidade de uma reflexão a partir deste para compreensão dos fenômenos da vida como um todo.

Para entender a teoria da reificação é necessário clarificar que a produção capitalista se baseia na mercadoria como um produto com certo valor de uso, ou seja, para atendimento de uma necessidade do consumidor, entretanto, desde que este possa ter um valor de troca rentável no mercado, pois é sabido que ao capital interessa sobremaneira a geração de lucro. Assim, ao lado do valor de uso criou-se em grande parte o valor de troca, com valor econômico, o que passou a sobressair em detrimento dos usos diversos de atendimento as necessidades humanas. Os fenômenos observáveis desta relação baseada no valor mercadológico inferem na esfera psíquica na medida em que apresentam uma certa ruptura da relação do homem com a natureza em termos concretos 
e qualitativos, isso porque destaca radicalmente a dimensão quantitativa desta e seus elementos. (Goldmann, 1979, p. 121)

O valor de troca passou a ocupar a consciência dos homens seja no estágio de produção e venda da mercadoria ou nas relações inter-humanas em geral, diferentemente do valor de uso que é mais característico da demanda da esfera privada, como Goldmann ressalta. (1979, p. 119/120)

Sob o capitalismo mercantil, as relações de troca tomam proporções de coisas mortas e inertes baseadas no preço. Esse aspecto influencia diretamente na estrutura psíquica pelo predomínio do abstrato e quantitativo. Tudo passa a ser regido pelo preço de forma a se submeter às leis cegas e "naturais" do mercado, onde resta ao homem a passividade diante das coisas inertes em detrimento de sua vocação ativa na realidade humana. Desta forma, a natureza humana perde seu sentido ao ficar inibida de exercer sua capacidade transformadora, bem como se distancia cada vez mais do produto de seu trabalho. Da mesma forma ocorre com a atividade humana que se tornou força de trabalho disponível no mercado com valor e preço próprio a ser negociado. Na verdade, tanto a coisa se torna autônoma em relação à ação humana, como a realidade humana passa a ganhar o caráter de coisa. (Goldmann, 1979, p. 122-125)

Para Goldmann, as conseqüências da reificação estão para além do campo econômico, influenciando os terrenos da vida humana como um todo. Desta forma, a formação do Estado burocrático moderno com uma administração e justiça institucionalizada foram meios de assegurar diretamente os interesses dos capitalistas. A economia como fenômeno autônomo fez do Estado e do Direito meios de administrar os interesses da classe dominante, mesmo que estes possam ter aparente autonomia. A presença de leis abstratas e impessoais baseada em um formalismo rigoroso que tem relação direta com a lógica reificada, colocando as funções exercidas pelo homem implicitamente e focalizando as relações de troca no nível da consciência do homem, de modo a se sobressair perante as funções humanas. Mas tal fato faz sentido na realidade capitalista na medida em que as relações se baseiam essencialmente na troca da coisa pelo dinheiro. As leis exteriores passam a regular/determinar as relações sociais em que o homem torna-se um ser passivo, sem ter a possibilidade de exercer vontade própria. (1979, p. 126-133)

\section{Reificação, produção cultural e dominação econômica}

No contexto desta sociedade capitalista a produção intelectual e cultural perde suas possibilidades de influência sob o campo da vida social e econômica, ficando restrita à vida privada com um caráter essencialmente subjetivo por se voltar para a consciência individual perdendo assim sua autenticidade por se encontrar distanciada da realidade objetiva. A vida econômica e o fenômeno da reificação têm influenciado intensamente tais campos, que de modo progressivo buscam também substituir a autenticidade subjetiva para sua total inautenticidade. Nesse sentido, a lógica da produção mercadológica tem atingido diretamente a produção cultural como meio rentável, nota-se isso, sobretudo, na produção cinematográfica e de edição literária, mesmo que a intenção seja subjetiva pelo 
valor de uso, mas de alguma forma tem como resultado final o lucro. A produção chega ao plano da psicologia reificada com a ruptura com a realidade cotidiana e o foco na alma profunda, distante da realidade. (Goldmann, 1979, p. 134-135)

Em síntese, as conseqüências da reificação se estendem às esferas da vida social e intelectual, na medida em que para além de seu fenômeno nos processos econômicos, desdobra-se para o nível da superestrutura de modo a reforçar tal ação sobre esta. A vida em geral passa a ser influenciada por esta tendência, sejam os campos mais ligados a estrutura econômica, como o Direito e a Política, bem como os mais afastados, como a vida intelectual, moral, religiosa, etc. (Goldmann, 1979, p. 131)

A reificação com o tempo foi progressivamente rompendo com a realidade social e a busca do humano, pela substituição de uma mera descrição de uma realidade social reificada inumana e sem significação, deixando realmente de lado, mesmo minimamente, a busca do humano de modo implícito ou eliminando-a de vez. O homem assim é cada vez mais reduzido ao estado de coisificação, totalmente sem expressão. (Goldmann, 1979, p. 137) Quanto mais especificamente à classe trabalhadora, pode-se até em parte dizer que o pensamento desta é o menos atingido pela reificação por estar mais ligado a solidariedade e não a liberdade, característica da ideologia liberal que esta classe desfruta superficialmente. O trabalhador ainda consegue estabelecer relações humanas mais diretas e solidárias na vida privada (família/amigos) e na vida econômica somente com os seus colegas de trabalho. Isso pelo fato do operário estar mais ligado na realidade humana, sobretudo, porque não é proprietário dos meios de produção e não vende para o lucro. Em contraposição, o patrão defende o que é seu e o trabalhador produz para o outro (patrão) e ainda pertence a este durante o processo de trabalho em si. Nesse sentido, Goldmann (1979, p. 143) defende a idéia de que é o operário que pode lutar contra a reificação, podendo unir sua qualidade de atitude mais geral de modo a concretizá-la na realidade, junto dos pressupostos filosóficos para que realmente isso seja possível. (Idem, pp. 140-151)

Porém, isso não significa que a reificação não esteja presente no pensamento da classe operária até porque sob o capitalismo tal fenômeno tem influenciado a vida humana em geral de modo a distanciar a unidade sujeito e objeto. A reificação penetra no espírito do operário através da influência ideológica de outras classes. (Idem, pp. 144-145) Inicialmente torna-se relevante resgatar o sentido que a produção cultural se configura no imaginário da sociedade capitalista. Assim, destacam-se dois aspectos importantes, o primeiro sobre a relação do artista e da produção em si e o segundo quanto à distribuição e o consumo da produção cultural.

O primeiro aspecto, por um lado, coloca em discussão os fatores de submissão dos artistas, sobretudo, face às dificuldades em assegurar a sua existência, o que tem impulsionado a inserção de muitos destes no mundo dos "negócios" da classe burguesa. Desde do período modernista, podemos verificar um processo mais profundo de contraposição da arte como valor de uso pela a arte como valor de troca, sendo ainda 
ambos de certa forma presentes nesse tempo. Mesmo assim, observamos que o campo da arte se tornou reflexo das relações capitalistas, passando gradualmente a lançar a arte e o artista como mercadorias que disputam entre si uma imposição social.

Desta forma, no que tange ao segundo aspecto, verifica-se que a produção cultural sob os efeitos das relações de troca se presentificam como objeto de consumo na medida em que as classes alta e média almejam adquiri-la restritamente em forma de mercadoria, portanto, distinta de seu significado enquanto produto cultural. Nesse sentido, a oferta cultural tem ao longo dos anos maximizado a lógica mercadológica na medida em que é possível constatar a alocação de recursos e ações focalizadas na promoção de eventos voltados para publicização de artistas no "ranking" de sucesso no mercado, bem como a distribuição da oferta de cultura em zonas geográficas mais próximas às classes altas e médias. Mesmo com algumas ações de cunho popular, destinadas aos bairros ocupados pelas classes de baixa renda, sobretudo, através de lonas culturais, estas nada mais têm servido à reprodução da publicização da produção cultural com vistas ao consumo em massa por esta classe.

As ações centradas na distribuição de cultura apontam para o rompimento sutil das fronteiras entre as classes sociais, onde a produção deixa de ser encarada pelas possibilidades de ligação com a origem social e passa a tão somente ter valor o lugar em que esta ocupa no imaginário das classes enquanto bem de consumo com valor de troca. Nesse sentido, a produção cultural deixa de se configurar primordialmente pelos seus aspectos objetivos de ligação com a realidade e formação da consciência de classe para se tornar mais um campo da vida humana penetrado pela alienação. O homem se aliena das relações sociais que estabelece com os seus pares na medida em que estas são falseadas pelas relações entre coisas. Isso confirma o que Fischer (1983) afirma sobre a desumanização no campo da arte e da literatura que se faz na medida em que o artista se aliena de seu mundo e do homem. Esse fenômeno é explicável no mundo capitalista pelo princípio de que as coisas é que possuem valor, o que da mesma forma acontece com o homem que também se torna um objeto entre outros. A arte também vai se caracterizando sob a forma desumana e desconexa da sociedade, como ainda o grande crescimento da indústria cultural de massa com produtos que ignoram a realidade do povo como um todo. (p.104-116)

Desta forma, identificamos que o processo de reificação chega a amplas proporções de modo a redimensionar as relações de troca como fim maior nas interações humanas.

Então, torna-se possível constatar a validade da teoria da reificação e seus desdobramentos nos diferentes campos do organismo social e, neste caso mais específico no campo da produção cultural, sobretudo, em função do alto nível de circulação de mercadorias presente no desenvolvimento do sistema capitalista.

\section{Conclusão}

[...]ver alguém não vendo é a melhor maneira de ver intensamente o que ele não vê. (Roland Barthes. Mitologias, 1982, p.32) Ao concluirmos este estudo sobre a cidade, o trabalho e a cultura na cidade do Rio de 
Janeiro, pensamos ser importante recuperarmos, metodologicamente, algumas das questões abordadas no contexto do trabalho de criação e estabelecimento do texto final que ora apresentamos.

A cidade moderna se configurou a partir das reformas empreendidas para adequação aos padrões do capitalismo mundial. O Rio de Janeiro como epicentro nacional foi alvo de ações reformistas modernizantes para remodelação de seu cenário socioeconômico e cultural. A cidade ao transformar sua imagem para o mundo modifica a existência de sua população, enquanto as elites buscam o status social europeu, as classes de baixa renda são arbitrariamente alocadas espacial e culturalmente em posição secundária à configuração modernizante da cidade. Esse processo desencadeou a intensificação da precarização dos serviços urbanos e da ocupação territorial. Por outro lado, a cidade não conseguiu alcançar plenamente seu projeto de modernidade pela estratificação social na medida em que a classe abastada e a classe de baixa renda passaram a estabelecer uma nova relação social, sobretudo, pela prestação de serviços. Nesse sentido, as reformas realizadas repercutiram diretamente nos padrões e hábitos da cidade e de seu habitante, configurando novos espaços e modos de vida.

Como vimos, a capital moderna em meados do século XX processa mudanças para inserção no quadro dos paradigmas industriais do capitalismo mundial. A cidade do Rio de Janeiro foi alvo do projeto nacional de modernização industrial, entretanto, este não se realizou de modo a se consolidar sob os padrões da produção industrial capitalista. A cidade nesse contexto se destacou pela centralização das transações administrativas e financeiras dos empreendimentos corporativos. As medidas industrializantes para a cidade foram em grande parte fracassadas, bem como junto a este processo a cidade perdeu seu prestígio nacional pela transferência da capital para Brasília.

Sendo assim, a cidade chega as transformações do atual regime de acumulação do capitalismo, pautado nos pressupostos da flexibilidade no nível da produção e das relações como um todo, com a intensificação de uma economia informal em função da crise estrutural de desemprego. No bojo das novas relações capitalistas, as atividades exercidas pela classe de baixa renda na cidade tornam-se cada vez mais um dos únicos meios possíveis de subsistência para a população, que desde das reformas realizadas no início do século cria formas de adaptação aos novos padrões estabelecidos. Nesse sentido, as medidas flexíveis adotadas nas relações de produção não são indiferentes para a população carioca que tradicional usa da flexibilidade nas atividades ligadas ao trabalho e as demais formas voltadas à subsistência.

A crise estrutural do desemprego e a exclusão do mercado formal pela reestruturação produtiva recuperaram antigas formas de trabalho e de acumulação primitiva. No presente estudo, destacamos, no contexto apresentado, o tradicional trabalho de reciclagem de artefatos industriais, que se intensificou mediante a imposição de mudanças nos padrões de produção e de consumo. A pesquisa empírica realizada com os trabalhadores que exercem esta atividade de reciclagem e a catalogação de matérias da imprensa escrita 
mostrou que os investimentos na área cultural estão em sua totalidade alocados na zona sul da cidade e a falta de ações para formação cultural do trabalhador com o objetivo de possibilitar a apropriação consciente da produção cultural. Os dados analisados foram relevantes para compreensão de alguns aspectos que indicam porque esses trabalhadores não são freqüentadores de grande parte dos espaços culturais. Observamos que as ações culturais na cidade, sobretudo, realizadas pela Secretaria Municipal de Culturas são marcadas pelas relações mercadológicas e pela divisão espacial desigual da produção cultural e de seus equipamentos.

Desta forma, os estudos em torno da teoria da reificação auxiliaram para análise das matérias da imprensa como ainda para ações colocadas em prática pelo poder público e pelos investimentos privados na cidade do Rio de Janeiro. As ações culturais identificadas mostraram que os efeitos da relação de troca estão também fortemente presentes no campo cultural na medida em que o oferecimento de sua produção se tornou objeto de consumo. A lógica para aquisição de um bem cultural está pautada neste como mercadoria, exigindo, por conseguinte, o seu consumo em massa. Assim, as relações estabelecidas no campo cultural se desdobram em relações alienantes pelo seu caráter mercadológico desvinculado dos aspectos objetivos de ligação com a realidade e formação de consciência de classe.

Em termos conclusivos, sabemos que muitos aspectos abordados são de conhecimento público, contudo, esperamos que os estudos aqui apresentados possam contribuir para a ampliação do modo como compreendemos hoje as relações entre o trabalho e a formação cultural do trabalhador na cidade sob o capitalismo. Finalmente, buscamos nos limites deste trabalho, contribuir na luta por uma sociedade mais transparente e mais justa.

\section{Bibliografia}

ARGAN, Giulio Carlo. Arte moderna. São Paulo: Martins Fontes, 1993.

FISCHER, Ernst. A necessidade da arte. Rio de Janeiro: Zahar, 1983.

GRAMSCI, Antônio. Os intelectuais e a organização da cultura. Rio de Janeiro: Civilização Brasileira, 1979.

GOLDMANN, Lucien. Dialética e Cultura. Rio de Janeiro: Paz e Terra, 1979. pp. 105-152.

HARVEY, David. Condição Pós-moderna. São Paulo: Edições Loyola, 1993.

LESSA, Carlos. Rio de todos os Brasis. Uma reflexão em busca de auto-estima. Rio de Janeiro: Record, 2001.

(orgs.). Rio de Janeiro: panorama sociocultural. Rio de Janeiro: Ed. Rio, 2004, pp. 09-18

"Trajetórias da cidade moderna". In ROEDEL, Hiran, VIEIRA, Fernando A. da C.,

MOURA, Roberto. Tia Ciata e a pequena África no Rio de Janeiro. Rio de Janeiro: FUNART, 1988.

REIS, Ronaldo Rosas. Educação e estética. Ensaios críticos sobre arte e formação humana no pósmodernismo. São Paulo: Cortez, 2006.

"Cinema, multiculturalismo e dominação econômica". In Crítica Marxista n.ำ 20. 
Campinas: CEMARX/Unicamp, Rio de Janeiro: Revan, 2005, pp. 139-150.

"Trabalho e conhecimento estético". In Trabalho, Educação e Saúde. Vol 2. Rio de Janeiro: Fiocruz, Escola Politécnica Joaquim Venâncio, 2004, pp. 227-250.

"Trabalho improdutivo e ideologia estética. As relações sociais de produção de arte e a formação estético-cultural no Brasil”. Caxambu, MG: 28. ${ }^{a}$ Reunião Anual da Associação Nacional de Pesquisa e Pós-graduação em Educação, 2005.

. "Pós-modernismo, globalização e formação estético-cultural do trabalhador urbano no Rio de Janeiro. Trajetória, posições e embates no campo simbólico". Niterói: UFF/FEUFF/SSE/Programa de Pós-Graduação em Educação, 2002. Brasília: CNPq. Projeto de Pesquisa, 2003.

REIS, Ronaldo Rosas; RODRIGUES, Viviane de Souza. "Notas teórico-metodológicas sobre a formação cultural do reciclador de bens de consumo". Comunicação apresentada no 14온 Seminário de Iniciação Científica. Niterói: UFF, CD ROM, 2004.

REIS, Ronaldo Rosas; RODRIGUES, Viviane de Souza. "Rio de Janeiro: reformas urbanas e trabalho urbano". Comunicação apresentada no 15 Seminário de Iniciação Científica. Niterói: UFF, CD ROM, 2005.

ROEDEL, Hiran. "Uma cidade de muitos lugares". In ROEDEL, Hiran, VIEIRA, Fernando A. da C., (orgs.). Rio de Janeiro: panorama sociocultural. Rio de Janeiro: Ed. Rio, 2004, pp. 19-56

TIRIBA, Lia. "Pedagogia(s) da produção associada: para onde caminha a economia popular?". Economia popular e cultura do trabalho: pedagogia(s) da produção associada. ljuí: UNIJUÍ, 2001. pp. 335-375

(*) O presente artigo teve como ponto de partida a minha participação na pesquisa "Pós-modernismo, globalização e a formação estético-cultural do trabalhador urbano no Rio de Janeiro" como bolsista do PIBIC-UFF/CNPq, sob a orientação do Prof.Dr. Ronaldo Rosas Reis. Posteriormente, o trabalho realizado serviu de base para a monografia homônima, apresentada em 2005, como requisito para a obtenção do grau no Curso de Pedagogia da Universidade Federal Fluminense.

(**) Pedagoga (UFF), vivi srodrigues@yahoo.com.br

[1] Em 2003, quando foram realizadas parte das entrevistas e do levantamento de fontes documentais, constavam da equipe de pesquisadores como bolsistas de IC do PIBIC-UFF/CNPq os alunos Luiz Gustavo Fernandes Ramos, do curso de Comunicação Social, e Flavia Figueiredo de Lamare, do curso de Pedagogia. 